\section{Development of the Maturity Matrix Dentistry (MMD): a primary care dental team development tool}

\author{
E. Barnes, ${ }^{1}$ E. P. Howells, ${ }^{2}$ K. Marshall, ${ }^{3}$ A. Bullock, ${ }_{1}^{4}$ J. Cowpe ${ }^{5}$ \\ and $\mathrm{H}$. Thomas ${ }^{6}$
}

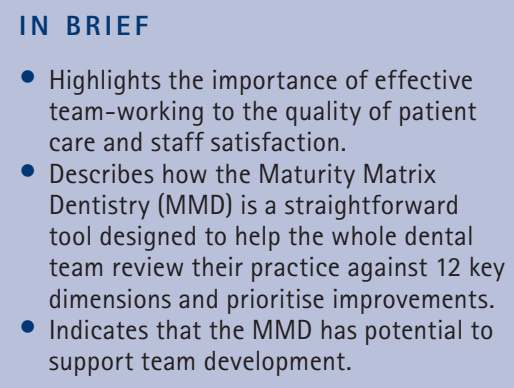

Objectives To adapt the Maturity Matrix (a self-evaluation practice development tool for medical primary care teams) for dentistry, creating the Maturity Matrix Dentistry (MMD), a team development tool for general dental practices. Methods The MMD was adapted by a multi-organisational dental working group and run from within the dental section, Wales Deanery. Individual feedback questionnaires were issued and the results used to refine the tool. It was piloted twice with a total of 67 practices (563 participants) with 104 participating twice. Results The MMD was considered a useful tool for dental practices; agreement was high across job roles. Following participant feedback, refinement was made to the terminology used and the ordering of some of the dimensions. Facilitator involvement in the group session was highly valued. In the pilot, $97 \%$ indicated they intended to use the MMD to improve practice and $77 \%$ said they would use it to carry out an audit. Of those participating in a second visit, 78\% reported an improvement against the dimensions and 83\% had carried out an audit or were in the process of doing so. Conclusions Dental teams indicated high levels of satisfaction with the process, and self-reported improvements against the MMD dimensions are encouraging for future use.

\section{INTRODUCTION}

There is a growing body of research evidence that team-working can make a substantial contribution to improvements in the quality of patient care, the efficient use of resources, staff satisfaction and wellbeing..$^{1,2}$ A wide-ranging literature review by the National Patient Safety Agency National Clinical Assessment Service ${ }^{3}$ found effective team-working was an important factor influencing dental practitioner performance. The GDC principles of dental team-working ${ }^{4}$ note that: 'Good dental care is delivered by a dental team. The quality of teamwork is closely linked to the quality of care the team provides. All members of the team contribute to the patient's experience of dental treatment'. $\operatorname{Rattan}^{5}$ notes that clinical governance

${ }^{1,4}$ Cardiff Unit for Research and Evaluation in Medical and Dental Education (CUREMeDE), School of Social Sciences, Cardiff University, Cardiff; ${ }^{2 *}$ Clinical Dental Adviser Welsh Government/Public Health Wales: 3,5,6 Wales Deanery Dental Section, Postgraduate Medical and Dental Education (PGMDE), Cardiff University, Cardiff

${ }^{*}$ Correspondence to: Mrs Elizabeth Howells Email: lisa.howells2@wales.nhs.uk

\section{Refereed Paper}

Accepted 15 March 2012

DOI: 10.1038/sj.bdj.2012.523

${ }^{\circ}$ British Dental Journal 2012; 212: 583-587 requires team-working at all levels in the organisation and that encouraging team participation is more likely to produce a patient-centred service. Effective teamworking is promoted by the team having clear shared aims. This paper sets out the development and testing of a tool designed to help the whole dental team review their practice and prioritise improvements.

\section{The Maturity Matrix}

In 1997, the Maturity Matrix (MM) was developed by a group of general medical practitioners and an organisational psychologist to assess the extent to which a primary medical care practice has developed. ${ }^{6}$ The MM was designed as a means of measuring current practice, allowing the practice team to identify key areas for improvement, prioritise any interventions and support improvements in quality.

Eleven dimensions, displayed in a grid or 'matrix', represent various aspects of clinical governance, for example, audit of clinical performance, prescribing and risk management (for a full list see Eriksson et $\left.a .^{7}\right)$. The cell at the top of each dimension represents the most basic standard that might be found, the bottom cell of the dimension is the 'gold standard'. All staff members take part in a facilitated team discussion to examine the practices' 'maturity' against this series of dimensions. The aim is to arrive at an agreed consensus profile for the practice and discuss future development needs.

Since its original development the MM has evolved further and is currently being used in several countries in Europe as the International Family Practice Maturity Matrix.6,8-11

\section{Developing the Maturity Matrix for dental teams}

The MM had been researched and developed in Wales and its principles wellestablished with local health boards (the equivalent of primary care trusts in England) and primary care medical practice teams. Although there is a range of well-researched team development tools available for general dental services (GDS) teams, a number require initial and/or continuing financial outlay, together with a time commitment ranging from around 8 hours to a regular input over the course of 6 to 12 months, which may act as a deterrent for some practices.

A MM for dental teams would build on learning from the MM to develop a 
tool that is effective, quick and simple to use. It would not require financial outlay from the practice. It could be used alone or prior to using another more detailed or time-demanding system. It would meet the need for a straightforward team development tool, which focuses on core quality and safety topics and that can be used in the practice by all team members. This paper outlines the process of developing the Maturity Matrix Dentistry (MMD) and explores its usefulness to primary care dental teams.

\section{METHODS}

\section{Developing the MMD}

When asked, ten representatives of five key dental organisations in Wales and one GDP all agreed there would be value in developing a MM for dental teams. The MMD was developed by a working group and run from within the Wales Deanery Dental Section, School of Postgraduate Medical and Dental Education (PGMDE), Cardiff University. The group included representatives from postgraduate dental education in Wales, general dental practitioners, PGMDE practice development tutors (PDTs), the Clinical Governance Support and Development Unit, Welsh Government (WG) and Cymru Alliance of Primary Care - Orientated Research Network (CAPRICORN), which developed the original MM. The group was supported by a multi-organisational steering group including representatives from the British Dental Association, Community Health Councils (CHC), local health boards and the National Public Health Service (now Public Health Wales). The working group agreed the topics that would make up the matrix dimensions and appropriate sublevels within.

\section{Piloting}

In phase 1 it was decided to include approximately 30 general dental practices in the pilot study. This was considered sufficient to include a range of practices (for example, NHS, mixed NHS/ private, specialist such as orthodontics, single-handed and multi-dentist, rural and urban) and large enough to highlight any problems with the process, whilst remaining manageable for the tutors involved.
Three PDTs in South and Mid Wales invited practices with whom they already had a working relationship and were chosen to represent a range of practice types. PDTs contacted practices to explain the MMD and obtain informed consent. The pilot phase was run over approximately six months to allow all invited practices to participate. No practices refused to take part.

In phase 2, all five PDTs in Wales were asked to recruit additional practices to take part via personal contact during practice visits or a letter to all practices that the PDT had a working relationship with, including those who had taken part in phase 1. A flexible timeframe was set for phase 2 to allow PDTs to recruit practices in accordance with their capacity and to fit with practice requirements. Recruitment rates varied considerably depending on the time available to each PDT and whether their region was urban or rural. Travel constraints in rural Wales impacted on the number of practices PDTs could visit. Recruitment in phase 2 was most successful in South West Wales where every practice that was approached eventually participated, whereas in North West Wales practices, five practices did not refuse to participate, but asked to delay this until they 'had more time'. In both phases, practices received a short information leaflet outlining the MMD aims, benefits and process for use.

In phase 1, the MMD was piloted with 31 practices (212 participants), and in phase 2 , with 36 practices (351 participants, 104 of who were using the MMD for the second time). In phase 1 , three NHS dental teams in a community dental service (CDS) participated after expressing an interest. In phase 2, only general dental practices were included.

Most of the participants were dental nurses (DN) (52\%, including those in dual roles) or dentists (32\%). Receptionists accounted for $8 \%$ and hygienist/therapists or practice managers were $4 \%$ each. There was no notable difference in the patterns of participation by job role in phase 1 and phase 2 .

The MMD was delivered through facilitated dental team sessions in practices. Facilitators were all experienced PDTs who required minimal training in using the MMD, although they had induction to ensure consistent application of the tool.
After the session, each participant completed a feedback questionnaire exploring their views on the process including the MMD matrix, its usefulness, the language used, the group sessions, the facilitator and the documentation provided. The questionnaires were designed by the working group, supported by CAPRICORN, and piloted informally by group member's practice teams. They were issued by the PDTs at the session and returned by post. Participants were informed before taking part that the three CPD hours would be credited upon receipt of a fully completed questionnaire. A sheet with identifying information was detached by an administrator and stored separately ensuring anonymity. The feedback was used to refine the MMD and the procedure was piloted again. Two versions of the feedback questionnaire were used in phase 2; one for those completing the MMD for the first time and one for those using it for the second time, which focused on improvements the practice had made as a result of using the MMD.

\section{Ethical approval}

The principles of the MM were already well researched and established within healthcare settings. ${ }^{6-12}$ Development of the MMD did not include any patients/ patient data/members of the public and as service evaluation it did not constitute research requiring ethical approval. Standard ethical procedures concerning informed consent, confidentiality, anonymity and the secure storage of data were maintained throughout.

\section{RESULTS}

\section{Developing the MMD}

The MMD was developed through a series of group discussions and was informed by:

1. Input from a $\mathrm{CHC}$ member who provided the patients' perspective and suggested that the first dimensions should be those of particular interest to dental patients

2. The recognised components of clinical governance for primary care dental teams ${ }^{13}$

3. The GDC core topics ${ }^{14}$

4. The Healthcare Standards for Wales (2005), ${ }^{15}$ which apply to all health services in Wales (now the Standards 
for Health Services in Wales, 2010) ${ }^{16}$

5. The 1000 Lives Plus programme methodologies for improvement. ${ }^{17}$

Whereas the final general medical practitioner MM had 11 dimensions, the MMD was developed with 12 dimensions in order to incorporate additional dentistryspecific topics such as radiological standards (Fig. 1).

Each dimension contained six sub-levels, against which the dental teams scored themselves (Fig. 2). The MM dimensions previously contained between five and seven sub-levels, ${ }^{12}$ whereas the MMD was designed from the start with a standardised number $(n=6)$ in order to make the scoring clearer.

The procedure for carrying out the MMD was largely as used for the $\mathrm{MM}^{12}$ with two key exceptions. To encourage self-directed learning, the MMD includes a 'sources of help and advice' document that practice teams can refer to after the group session. The document is updated regularly and includes resources relevant to each of the twelve dimensions: electronic links to educational and advisory websites, references for further reading and other local sources of information and support.

The MM is facilitated by local health boards who hold the contracts for NHS primary care practitioners. To reinforce its developmental and educational aims the MMD has been promoted through, and facilitated by the Dental Section PGMDE and the School of Dentistry, Cardiff University. The MMD is administered and facilitated by PDTs who are part of the professional support service of the Dental Section, PGMDE in the Wales Deanery.

\section{Participant feedback}

In phase 1 of the study, just over 80\% of respondents were happy with the language used in the MMD dimensions; following refinement this increased to $96 \%$ in phase 2 . In phase 1 some participants, particularly those in non-clinical roles, found some terminology slightly confusing until it was explained by the facilitator. Therefore changes were made:

- Abbreviations and acronyms were clarified

- Maturity levels in some dimensions were rewritten and the order of some sub-levels was changed

- Dimension headings were amended (for example, 'practice meetings for all staff' was changed to 'team meetings and communication')

- The title was revised from 'Maturity Matrix Dentistry' to 'Maturity Matrix Dentistry - self-evaluation tool'.
Over $90 \%$ of respondents thought the MMD was a useful tool for dental teams in both phases (97\%/94\%). When examined by job role, hygienists/therapists, practice managers and those with combined job roles showed 100\% agreement; the lowest score was from dentists, at 93\%. In phase 1, CDS participants considered the MMD was better tailored to general dental practice, so phase 2 targeted GDS only.

Space was provided for additional comments and responses were typically positive:

'It helped a lot and I understood more once the meeting was finished' - Dental nurse.

1. Clinical assessment and clinical risk management

2. Disinfection and decontamination (infection prevention and control - IPC)

3. Radiological standards

4. Legal and ethical

5. Patient experience and handling feedback

6. Health and safety

7. Safety incident reporting - including patient safety reporting

8. Continuing professional development (CPD)

9. Audit of clinical performance

10. Evidence-based practice

11. Staff employment and wellbeing

12. Team meetings and communication

Fig. 1 The final MMD dimensions

\begin{tabular}{|c|c|c|c|}
\hline $\begin{array}{l}\text { Core topic } 1^{*} \\
\text { Clinical assessment and } \\
\text { clinical risk management }\end{array}$ & $\begin{array}{l}\text { Core topic } 2 \\
\text { Disinfection and decontamination } \\
\text { (infection prevention and control - IPC) }\end{array}$ & $\begin{array}{l}\text { Core topic } 3 \\
\text { Radiological standards }\end{array}$ & $\begin{array}{l}\text { Core topic } 4 \\
\text { Legal and ethical }\end{array}$ \\
\hline $\begin{array}{l}\text { 1.1 Patients have up-to-date } \\
\text { medical history on record }\end{array}$ & $\begin{array}{l}\text { 2.1 Evidence of basic IPC procedures } \\
\text { only and awareness of HTM-01-05 }\end{array}$ & $\begin{array}{l}\text { 3.1 No written radiological protection } \\
\text { systems in place }\end{array}$ & $\begin{array}{l}\text { 4.1 All staff are appropriately } \\
\text { registered with the GDC and } \\
\text { provide annual evidence of this }\end{array}$ \\
\hline $\begin{array}{l}1.2 \text { Patients' medical and social } \\
\text { history influences treatment planning }\end{array}$ & $\begin{array}{l}2.2 \text { The practice environment is } \\
\text { kept clean, well-maintained and } \\
\text { fit for purpose }\end{array}$ & $\begin{array}{l}3.2 \text { Basic written radiological systems } \\
\text { in place }\end{array}$ & $\begin{array}{l}\text { 4.2 All staff are aware of their } \\
\text { responsibilities for patient } \\
\text { confidentiality and receive } \\
\text { appropriate training P2 }\end{array}$ \\
\hline $\begin{array}{l}\text { 1.3 Patients records are up-to-date, } \\
\text { complete and stored safely }\end{array}$ & $\begin{array}{l}2.3 \text { Practical IPC written procedures } \\
\text { in place but not regularly reviewed }\end{array}$ & $\begin{array}{l}\text { 3.3 Radiation protection adviser } \\
\text { and radiation protection supervisor } \\
\text { appointed (IR(ME)R 2000) }\end{array}$ & $\begin{array}{l}\text { 4.3 All staff have appropriate CRB2 } \\
\text { checks with records kept safely in an } \\
\text { appropriate place P5 }\end{array}$ \\
\hline $\begin{array}{l}\text { 1.4 Practice team have received } \\
\text { basic training in dealing with } \\
\text { medical emergencies }\end{array}$ & $\begin{array}{l}2.4 \text { Regular review of IPC policy and } \\
\text { procedures and compliance with } \\
\text { essential requirements of HTM-01-05 }\end{array}$ & $\begin{array}{l}\text { 3.4 Relevant staff have radiological } \\
\text { training and continuing education } \\
\text { in compliance with IR(ME)R } 2000\end{array}$ & $\begin{array}{l}\text { 4.4 Registered staff have appropriate } \\
\text { medico-legal indemnity }\end{array}$ \\
\hline $\begin{array}{l}1.5 \text { The practice has appropriate } \\
\text { emergency equipment, which is } \\
\text { available when required and all } \\
\text { staff know where it is located }\end{array}$ & $\begin{array}{l}2.5 \text { Evidence of practical compliance } \\
\text { with advice sheet } \mathrm{A} 12 \text { and } \\
\text { HTM-01-05 }\end{array}$ & $\begin{array}{l}3.5 \text { Evidence of ongoing quality } \\
\text { assurance in place and subsequent } \\
\text { actions to improve quality }\end{array}$ & $\begin{array}{l}\text { 4.5 Staff understand their } \\
\text { responsibilities in respect of GDC } \\
\text { guidance on standards for dental } \\
\text { health professionals, including } \\
\text { equality and diversity }\end{array}$ \\
\hline $\begin{array}{l}\text { 1.6 Practice team have annual train- } \\
\text { ing by approved trainer in dealing } \\
\text { with medical emergencies, use of } \\
\text { emergency drugs and defibrillator }\end{array}$ & $\begin{array}{l}\text { 2.6 Evidence of continued training, } \\
\text { updating and audit of compliance } \\
\text { with relevant protocols }\end{array}$ & $\begin{array}{l}\text { 3.6 Evidence of radiological audit } \\
\text { within last two years and any neces- } \\
\text { sary steps taken to improve quality }\end{array}$ & $\begin{array}{l}\text { 4.6 Evidence that practice team are } \\
\text { kept up-to-date on their ethical and } \\
\text { legal responsibilities P2 }\end{array}$ \\
\hline
\end{tabular}

Fig. 2 Four example dimensions from the MMD grid 
It provided insight into the practice's current status and areas that required improvement:

'To enable [the] practice as a team to evaluate their current position and to move forward' - Dentist.

Reassurance they are currently functioning well:

'Reassures that practice is largely up to date in all dimensions' - Dentist.

Reinforcement of regulations or guidelines:

'Makes the team aware of clinical governance and the importance of self-evaluation as a team' - Practice manager.

Facilitator support was considered very helpful (94\%/97\%). From the additional comments we saw that respondents valued the facilitator's ability to constructively involve every member of the team in the group session. That facilitators were dental clinicians was seen as beneficial and aided trust in their feedback. They felt the facilitator delivered all information clearly, answered all questions fully, provided extra information and identified resources to support progress. No suggestions for refinement of the facilitator role were made.

In phase 2, 66\% of those who were completing the MMD for a second time also reported using the sources of help document to find additional information.

\section{Promoting audit}

In phase $1,77 \%$ of respondents said they would use the MMD to carry out an audit. Forty-five percent of respondents who were completing the MMD for the second time reported that they had; 38\% reported being in the process of planning or carrying out an audit. Topics identified for audit included:

- Dimension 2: disinfection and decontamination

- Dimension 3: radiological standards

- Dimension 5: patient experience and handling feedback

- Dimension 6: health and safety

- Dimension 10: evidence-based practice.

Interestingly, two subjects selected for audit were associated with a dimension but not specifically noted: smoking cessation (dimension 10: evidence-based practice) and water line checks (dimension 2: disinfection and decontamination). As a result the relevant sub-levels were enhanced to include these terms or to refer to specific guidance.

\section{Making a difference}

From the pilot, examples were collated of how the MMD has made a difference. Examples include how feedback triggered the development of national guidance (a), the development of training (b-e) and impact on practices (f-i).

a): Child protection and protection of vulnerable adults (POVA) are included in WG Standards for Health Services as 'safeguarding'. Using the MMD, dental teams consistently noted a lack of understanding of POVA, although they had clear understanding and evidence of training in child Protection. As a result, Public Health Wales set up a multi-disciplinary group to develop guidance on safeguarding for dental teams, which has been issued to all dental teams in Wales. ${ }^{18}$

b): Indemnity for DNs featured frequently. This included not only having appropriate indemnity but also reviewing those available to DNs and selecting the most appropriate. It was not unusual for DNs to assume their employers had arranged indemnity cover, but even where they had, DNs were often unable to evidence it for their own records and security. This information has been used by the Dental Section, PGMDE, to review its provision of training for DCPs.

c): Similar uncertainty was expressed about Criminal Record Bureau (CRB) checks, specifically which members of the dental team require a CRB check and how to progress this.

d): Very few practices included the whole dental team in audit, it was often seen as an activity for dentists. As a result, the Dental Section, PGMDE, is developing and piloting a practicebased audit training programme for DCPs. Sixteen practices have tested the programme, which has been well received to date.

e): Appraisal was limited or sporadic and some members of the team had no understanding of appraisal or its value. This added to the impetus in Dental Section, PGMDE to develop effective appraisal systems. A pilot scheme is underway to test three systems of appraisal with dental teams in Wales.

f): As a result of using MMD, more practices formalised their practice meetings by introducing agenda and minuting. Some added a training element as a means of contributing to general CPD.

g): Using MMD prompted revisions to practice protocols. One practice reviewed their system to ensure that patient medical history is always up to date and another revised their infection control protocol.

h): Using the MMD encouraged dental team members to undertake audits (see section 'promoting audit'). There is evidence from audit tutors of requests for support with audits following use of MMD and anecdotal evidence of increased requests for practice-based training on health and safety.

i): Following the suggestion of one practice manager, the practice is reviewing one dimension per month at a practice meeting. It was noted that very conveniently, there are 12 dimensions.

j): The MMD has been adapted by a researcher in Slovenia and is the subject of his $\mathrm{PhD}$. Another dentist undertaking an MSc study on quality and safety will review the MMD in depth as a tool for self-assessment in the CDS.

\section{DISCUSSION}

Since its development the MMD has been modified following feedback from dental teams and facilitators or updated as circumstances require. For example, when the former healthcare standards for Wales became the Standards for Health Services in Wales in April 2010. ${ }^{16}$ The MMD can be revised quickly to ensure it stays in line with current practice.

The MMD has an inbuilt flexible scoring system to allow the team to assess its level of maturity against each of the 12 dimensions. The assessment does not require participants to calculate a practice 'score' or average out the practice maturity, but acknowledges that the practice can be at different levels of maturity in each dimension. It also allows different staff groups 
- or even individuals - to recognise they are at different stages. It allows the team to demonstrate they have discussed and considered the clinical governance components in each of the 12 dimensions, and subsequently to identify and prioritise those aspects they want to improve.

The acceptance by dentists of the developing role of dental care professionals (DCPs) is crucial in allowing a shift towards greater team-working. ${ }^{3}$ DCPs in particular welcomed the MMD and facilitators noted that DCPs often requested to 'be the person who led on' improving a dimension.

Feedback on facilitators was consistently positive. The facilitators are all PDTs who have developed effective and ongoing working relationships with general dental practice teams. This contrasts with facilitators used in the MM who were employed by the general medical practice's contracting local health board and not therefore able to provide ongoing educational and practice development support after administration of the tool. In addition, formal and informal feedback from MMD has helped to inform topics for the training programme of the Dental Section, PGMDE of the Wales Deanery.

Although only 66\% reported using the 'sources of help and advice' document, it should be noted that these results are per individual and not per practice. For practical reasons it is likely that each team would have one or two nominated staff members responsible for checking information and guiding future improvements and therefore not every team member would need to use the document.

\section{Challenges and drawbacks of the MMD}

The MMD relies on the team being open, honest and prepared to contribute to their facilitated session. The team is also responsible for taking forward their improvement work. While they are not required to submit evidence of their agreed level of maturity or improvements made, the PDTs have a continuing relationship with practices which has enabled them to informally assess progress. PDTs reported a number of challenges when facilitating the MMD. Although the session is held when the practice is 'closed' for an hour or so (for example, over lunchtime), it is impossible to eliminate all distractions such as urgent patient enquiries. It can be challenging to allow all members to contribute as fully as they would like when teams have more than eight members. Human factors also play a part with dominant or sceptical team members having to be appropriately but fairly handled.

\section{Limitations and learning points}

The MMD was developed as a practical tool, building on the work of MM to ensure its acceptability and appropriateness for dental teams. Recruitment procedures varied amongst the PDTs, with personal contact reaping the greatest returns. We remain unaware whether recruitment method (that is, their prior relationship with their PDT) or the prospect of the MMD as a process influenced response rates in phase 2 . Additionally, while the development process allowed for systematic, piloting and refinement of the MMD, systems of recording did not enable practices to be tracked over time. It would have been valuable to explore in more detail the perceived value of the MMD for both practices and individual team members who had used it more than once. The findings from the self-rated improvements and their ability to be generalised must be interpreted with these issues in mind. However, the high reported usefulness and fact that practices were keen to repeat the process in order to assess improvement was an encouraging finding.

\section{CONCLUSION}

Since its development the MMD has been used with a variety of GDS teams. It has been very well received as a straightforward team development tool, which provides all team members with the opportunity to discuss key clinical governance issues and identify areas for improvement. The support of facilitators is valued by all team members and seen as essential to its success. Using the MMD on the practice premises is very welcome, as is allocation of verifiable CPD. Preliminary findings indicate self-reported practice improvements and increased audits following use of MMD. Not only has the MMD been useful for teams, but as importantly it has resulted in the development of national guidance on safeguarding and the identification of training needs. The MMD has considerable potential to support dental team development.

The authors would like to thank all the PDTs who facilitated sessions, the practices who participated and Kate Croydon and Richard Williams from the Dental Section, the Wales Deanery, who supported the process. The Dental Section, the Wales Deanery in Cardiff University is happy to share the MMD with colleagues who may want to trial it.

1. Borrill C, West M. How good is your team? A guide for team members. Birmingham: Aston Centre for Health Service Organisation Research, 2002.

2. National Health Service Management Executive. Nursing in primary care - new world, new opportunities. Leeds: NHSME, 1993.

3. National Patient Safety Agency, National Clinical Assessment Service. Factors influencing dental practitioner performance: a literature review. NCAS, 2011.

4. General Dental Council. Principles of dental team working. London: GDC, 2009.

5. Rattan $R$, Chambers R, Wakely G. Clinical governance in general dental practice. Oxford: Radcliffe Publishing Ltd., 2002.

6. Rhydderch M, Edwards A, Marshall M et al. Maturity matrix: a criterion validity study of an instrument to assess organisational development in European general practice. Qual Prim Care 2006; 14: 133-143.

7. Eriksson T, Siersma V D, Løgstrup L, Buch M S, Elwyn $G$, Edwards A. Documenting organisational development in general practice using a group-based assessment method: the Maturity Matrix. Qual Saf Health Care 2010; 19: e37.

8. Elwyn G, Bekkers M J, Tapp L, Edwards A et al. Facilitating organisational development using a group-based formative assessment and benchmarking method: design and implementation of the International Family Practice Maturity Matrix. Qual Saf Health Care 2010; 19: e48

9. Buch M S, Edwards A, Eriksson T. Participants' evaluation of a group-based organisational assessment tool in Danish general practice: the Maturity Matrix. Qual Prim Care 2009; 17: 311-322.

10. Edwards A, Rhydderch $M$, Engels $Y$ et al. Assessing organisational development in European primary care using a group-based method: a feasibility study of the Maturity Matrix. Int J Health Care Qual Assur 2010; 23: 8-21.

11. Loegstrup L, Edwards A, Waldorff F B, Siersma V D, Buch M S, Eriksson T. GP and staff evaluation of the maturity matrix as a tool to assess and improve organisational development in primary care. Int $J$ Health Care Qual Assur 2009; 22: 686-700.

12. Elwyn G, Rhydderch M, Edwards A et al. Assessing organisational development in primary medical care using a group based assessment: the Maturity Matrix. Qual Saf Health Care 2004; 13: 287-294.

13. British Dental Association. Continuing professional development, clinical governance, clinical audit and peer review. London: British Dental Association, 2007.

14. General Dental Council. Standards for dental professionals. London: GDC, 2006.

15. Welsh Government. Healthcare Standards for Wales. 2005.

16. Welsh Government. Doing well, doing better: Standards for Health Services in Wales. Welsh Government, 2010.

17. 1000 Lives Plus. Online information available at www. 1000livesplus.wales.nhs.uk (last accessed May 2012).

18. Public Health Wales. Guidance for safeguarding children and vulnerable adults in general dental practice. Public Health Wales, 2011. 